\title{
BMJ
}

\section{Effect of antibiotic prescribing in primary care on antimicrobial resistance in individual patients: systematic review and meta-analysis}

${ }^{1}$ Academic Unit of Primary Health

Care, NIHR National School for

Primary Care Research,

Department of Community Based

Medicine, University of Bristol,

Bristol BS8 2AA

${ }^{2}$ Department of Social Medicine, Canynge Hall, University of Bristol, Bristol BS8 2PS

${ }^{3}$ Department of Microbiology, Bristol Centre for Antimicrobial Research and Enterprise,

Southmead Hospital, Bristol BS9 3HU

${ }^{4}$ Department of Primary Health Care, NIHR National School for Primary Care Research, Oxford University, Headington, Oxford OX3 7LF

Correspondence to: A Hay alastair.hay@bristol.ac.uk

Cite this as: BMJ 2010;340:C2096 doi:10.1136/bmi.c2096

\section{Céire Costelloe, research associate, ${ }^{1}$ Chris Metcalfe, senior lecturer in medical statistics, ${ }^{2}$ Andrew Lovering, consultant clinical scientist, ${ }^{3}$ David Mant, professor of general practice, ${ }^{4}$ Alastair D Hay, consultant senior lecturer in primary health care}

\section{ABSTRACT}

Objective To systematically review the literature and, where appropriate, meta-analyse studies investigating subsequent antibiotic resistance in individuals prescribed antibiotics in primary care.

Design Systematic review with meta-analysis.

Data sources Observational and experimental studies identified through Medline, Embase, and Cochrane searches.

Review methods Electronic searches using MeSH terms and text words identified 4373 papers. Two independent reviewers assessed quality of eligible studies and extracted data. Meta-analyses were conducted for studies presenting similar outcomes.

Results The review included 24 studies; 22 involved patients with symptomatic infection and two involved healthy volunteers; 19 were observational studies (of which two were prospective) and five were randomised trials. In five studies of urinary tract bacteria (14348 participants), the pooled odds ratio (OR) for resistance was 2.5 (95\% confidence interval 2.1 to 2.9 ) within 2 months of antibiotic treatment and 1.33 (1.2 to 1.5) within 12 months. In seven studies of respiratory tract bacteria (2605 participants), pooled ORs were 2.4 (1.4 to 3.9) and 2.4 (1.3 to 4.5) for the same periods, respectively. Studies reporting the quantity of antibiotic prescribed found that longer duration and multiple courses were associated with higher rates of resistance. Studies comparing the potential for different antibiotics to induce resistance showed no consistent effects. Only one prospective study reported changes in resistance over a long period; pooled ORs fell from 12.2 (6.8 to 22.1) at 1 week to 6.1 (2.8 to 13.4) at 1 month, 3.6 (2.2 to 6.0) at 2 months, and 2.2 (1.3 to 3.6) at 6 months.

Conclusions Individuals prescribed an antibiotic in primary care for a respiratory or urinary infection develop bacterial resistance to that antibiotic. The effect is greatest in the month immediately after treatment but may persist for up to 12 months. This effect not only increases the population carriage of organisms resistant to first line antibiotics, but also creates the conditions for increased use of second line antibiotics in the community.

\section{INTRODUCTION}

One of the most pressing problems faced by healthcare services is the increasing prevalence of antimicrobial resistance. Compounded by a diminishing number of new agents entering clinical practice, such resistance is widely recognised as a major threat to public health. ${ }^{1}$ In general practice, there are concerns that some common infections are becoming increasingly difficult to treat and that illnesses due to antibiotic resistant bacteria may take longer to resolve. ${ }^{2}$

Some antimicrobial resistance may result from indiscriminate or poor use of antibiotics. In response, initiatives at the local, national, and international levels, are trying to promote "antibiotic stewardship," with the goal of improving the appropriateness of antimicrobial use. However, such initiatives rely for success on the continuing education of prescribers and patients, which needs to be supported by high quality evidence linking antimicrobial use to the emergence of resistance.

Although many countries have been successful in reducing primary care prescribing of antimicrobials, primary care is still responsible for the majority of antibiotics prescribed to people. ${ }^{34}$ Much of this use is in the treatment of suspected respiratory infection and levels of prescribing vary widely within ${ }^{5}$ and between countries, ${ }^{6}$ suggesting that further reductions are possible. However, there are many barriers to reducing the inappropriate use of antimicrobials, including: patient and practitioner expectations, ${ }^{7}$ lack of patient awareness of the problems caused by antimicrobial resistance, ${ }^{8}$ and a perception in primary care clinicians and patients that antibiotic resistance is only a theoretical $^{9}$ or minimal ${ }^{10}$ risk. Although the reason for such views being held is unclear, it may in part be because some previous studies have only investigated the relation between prescribing and resistance with population level data. ${ }^{1-13}$ Consequently for clinicians, whose primary concern is the unwell individual, the 
impact of antimicrobial use on the prevalence of societal resistance may not be an important consideration. ${ }^{14}$ To reduce prescribing, it may therefore be important to highlight the effect of antimicrobial use on emergent resistance for individuals. ${ }^{15}$

To date, a limited number of good quality studies have reported on the relation between prescribing and prevalence of resistance for individuals treated in primary care, ${ }^{16}$ and to the best of our knowledge no systematic reviews have been published in this area. ${ }^{17-19}$ We have therefore undertaken a systematic review and meta-analysis of studies where the effect of antimicrobial use on the emergence of resistance has been assessed for individual patients in primary care. We were particularly interested in quantifying the strength and duration of any association as well as identifying which antibiotics were most and least likely to cause resistance.

\section{METHODS}

\section{Search strategy}

The search strategy was designed to identify observational and experimental studies: conducted in any country; investigating relations between primary care prescribed antibiotics and antimicrobial resistance in bacteria sampled from any body site; analysed at the level of the individual; and published in any language.

We searched the MEDLINE (1955 to May 2009), EMBASE (1980 to May 2009), and Cochrane databases using the OVID interrogation software. We also searched for grey literature and unpublished work using the ISI web of knowledge, which identifies journal articles, patents, websites, conference proceedings, and open access material. MeSH terms used included "ambulatory care", "drug resistance", "antimicrobial resistance", and "bacterial resistance". We combined these terms with selected text word searches that included: "primary care", "ambulatory care", "family practice", and "antibiotics" (see box for full search strategy). Additionally, we screened the reference lists of selected papers and wrote to authors who appeared more than once in our search asking for details of other published and unpublished studies. We performed citation searches of all full text papers.

\section{Study selection}

Studies were eligible for inclusion if they investigated and reported quantitative relationships between primary care prescribed antibiotics and subsequent antimicrobial resistance at the level of the individual. Studies were excluded if they were not original research, did not measure antibiotics prescribed in primary care, or were ecological studies.

Two independent reviewers (CC, ADH) screened the title and abstract of papers identified by the electronic searches, completing an inclusion/exclusion form for all papers. We retrieved full copies of included papers, each of which was independently reviewed for eligibility by two authors (CC and either DM, $\mathrm{CM}, \mathrm{ADH}$, or $\mathrm{AL})$. Disagreements were resolved by discussion with a third author.

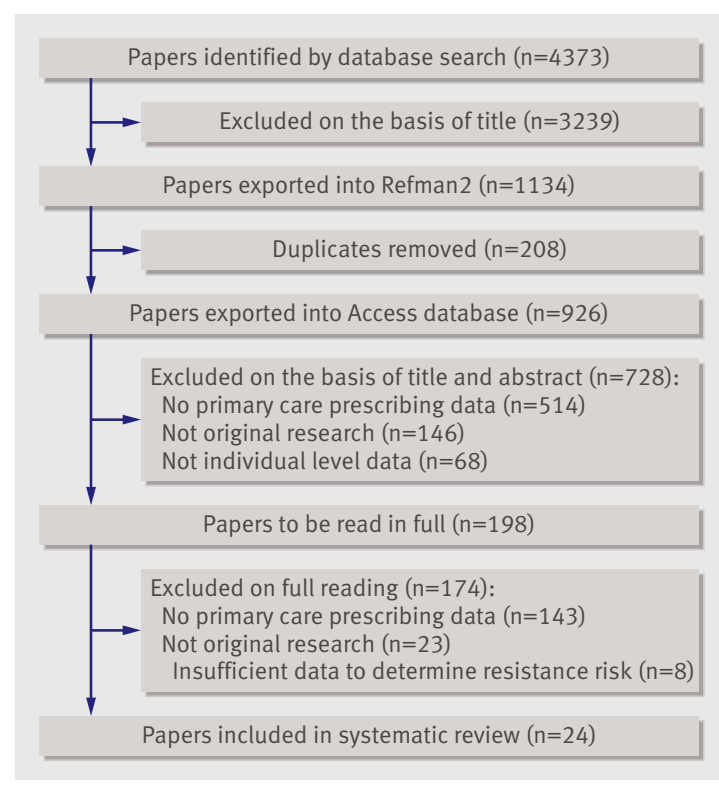

Fig 1| Stages of inclusion/exclusion and evaluation of studies in the systematic review

\section{Data extraction and quality assessment}

Full articles were independently reviewed for quality and data extracted using a purpose-designed form by two reviewers (CC and one other). Disagreements were resolved by discussion with a third author $(\mathrm{ADH})$. Where data extraction was difficult or unclear, the paper's author was contacted for clarification.

The explanatory variables extracted included: study design; description of participants; recruitment location; prescribed antibiotic types; dose and number of courses; and time between antibiotic exposure and measurement of resistance. Time was measured as the exact time at which individuals took antibiotics, or time period during which antibiotic prescribing was recorded, before measurement of resistance.

The outcome data extracted were: bacteria type; sampling location; the antibiotics to which resistance was measured; and the method of measuring resistance.

We agreed that the most important quality criteria for studies quantifying the relation between prescribing and resistance were (1) a reliable measure of antibiotic exposure; (2) a reliable measure of resistance; (3) unbiased control selection; (4) ability to identify incident cases (that is, patients' bacteria were known to be non-resistant before exposure to antibiotics); (5) adjustment for key confounders such as recent hospitalisation or instrumentation of the urinary tract. Each study was rated according to these criteria and any studies that met fewer than three criteria present were not included in the meta-analyses.

\section{Data synthesis and analysis}

All analyses were done using STATA version 10. The outcome measure was the odds ratio (OR) of resistance in participants exposed to antibiotics compared with those who were unexposed. The ORs and associated 
MEDLINE and EMBASE search strategy

1 exp Drug Resistance, Microbial/145030

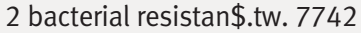

3 antibiotic resistan\$.tw. 36098

4 family practice (no related terms) 1530

5 antimicrobial resistance (no related terms) 2042

6 drug resistan\$.tw. 77383

7 primary care (no related terms) 10339

8 ambulatory care (no related terms) 913

9 family practice (no related terms) 1530

10 exp Primary health care/91893

11 antibiotics (no related terms) 10404

122 or 3 or 4 or 6 or 7232539

135 or 8 or 9 or 10 or 1197137

Combination of 12 and 134373

$\$$ indicates truncation. tw=text word. No related terms specifies search words only

95\% confidence intervals $(\mathrm{CI})$ were tabulated by bacterium type and sampling location (for example, Escherichia coli from the urinary tract) and by time since exposure to antibiotic. Heterogeneity was measured using the $\mathrm{I}^{2}$ statistic and the null hypothesis of no heterogeneity was tested using the $Q$ statistic generated from the $\chi^{2}$ test. For analyses in which we found evidence of heterogeneity, a random effects model was used to estimate the pooled OR. Where meta-analyses involved non-randomised studies the unadjusted OR was calculated or used, since unadjusted ORs were available for many more studies than the adjusted OR.

We carried out a meta-analysis of the adjusted results, although we only had sufficient data to do this for the studies examining resistance in urinary tract bacteria at the 0-3 month period. Meta-regression was used to investigate differences in the OR between exposures and resistance across different time periods. The meta-regression analyses could each include several estimates based on overlapping data from the same study; a sensitivity analysis based on the bootstrap method was used to check for overestimation of the precision of estimates. Finally, we produced funnel plots to look at the possibility of small study effects, one cause of which is publication bias. All methods were undertaken according to the $\mathrm{MOOSE}^{20}$ and QUOROM ${ }^{21}$ guidelines for the conduct and reporting of systematic reviews. During the course of the study the PRISMA ${ }^{22}$ guidelines were developed and we have also adhered to these where relevant.

\section{RESULTS}

Study characteristics

Database searches identified 4373 potential studies of which 3239 were excluded on the basis of title (fig 1). Assessment of title and abstract led to the identification of 208 duplicate studies and the exclusion of 728 studies not meeting eligibility criteria. For 514 studies, no primary care prescribing data were presented and 146 of the studies identified were reviews, and not original research. Sixty-eight articles were ecological studies and did not report on resistance individuals. The remaining 198 papers were read in full, and of these 174 were excluded on the basis of not including primary care prescribing data (143), not reporting original research (23), and not reporting sufficient evidence to determine resistance risk (8). Twenty-four papers were included in the review.

Table 1 summarises the characteristics of the final 24 studies included in the review. ${ }^{17-1923-43}$ These consisted of five randomised controlled trials (RCTs) and 19 observational studies, two of which were prospective, and 17 retrospective controlled observational or casecontrol studies. These studies investigated effects in 15505 adults and 12103 children. Although not an inclusion criterion, all studies were based in countries where antibiotics are available by prescription only. Twenty-two studies sampled bacteria from patients with symptomatic infection: urinary tract infection (seven studies); ${ }^{17-1923-2527}$ respiratory tract infections (seven); ${ }^{28-34}$ otitis media (two); ${ }^{3642}$ chronic obstructive pulmonary disease (one) ${ }^{37}$ meticillin resistant Staphylococcus aureus (MRSA) infection (four); ${ }^{38-41}$ and trachoma in children (one). ${ }^{43}$ Two studies examined asymptomatic healthy adult volunteers. ${ }^{1835}$ Studies presented a wide range of antibiotic exposure analyses including those for: macrolides (eight studies); ; $1924293133-35374243$ penicillins (five); ${ }^{1727323435}$ sulphonamides and trimethoprim (six); ${ }^{17-1923-25}$ cephalosporins (six); ${ }^{273334363742}$ tetracyclines (two); ${ }^{3337}$ quinolones (two); ${ }^{3337}$ nalidixic acid (one); $;^{27}$ metronidazole (one); ${ }^{24}$ nitrofurantoin (one); ${ }^{27}$ and "any antibiotic" (seven) 18253038-41 given between two and 104 weeks before measurement of antibiotic resistance. Adherence to antibiotic regime was not assessed in most of the studies as they were retrospective and researchers were only able to measure prescribing from patients' records or questionnaires, though in one of the RCTs ${ }^{32}$ adherence was measured by recording medicine bottle weights at various time points throughout the study.

Table 2 reports the quality assessment of the studies. Only one study ${ }^{35}$ met all five criteria. Three studies, ${ }^{25-27}$ all of urinary tract bacteria, met fewer than three criteria and were excluded from the metaanalyses.

\section{Resistance in urinary bacteria}

Of the eight studies investigating effects on urinary bacteria, one was an antibiotic comparison study ${ }^{21}$ (table 1). The remaining seven studies reported comparisons between no treatment and prescription of any antibiotic, ${ }^{182523}$ amoxicillin, ${ }^{19}$ trimethoprim, ${ }^{17} 1924$ and ofloxacin ${ }^{25}$ in relation to resistance to ampicillin, ${ }^{19}$ trimethoprim, ${ }^{17-1923-25}$ sulphonamides, ${ }^{24}$ or ciprofloxacin. ${ }^{25}$ Five were of sufficient quality to be included in the meta-analysis. ${ }^{17-192423}$ Estimates from these studies were grouped according to the periods over which exposure was measured and represented on a forest plot (fig 2). This plot shows that at all time 
Table 1 Study characteristics (by reference number)

\begin{tabular}{|c|c|c|c|c|c|c|c|c|c|c|c|}
\hline Study & Design & $\mathrm{n}$ & Participants & Recruitment & Bacteria & Sample site & Method & $A B$ used & $\begin{array}{l}\text { AB to which } \\
\text { resistance } \\
\text { measured }\end{array}$ & $\begin{array}{c}\text { Time* }^{*} \\
\text { (months) }\end{array}$ & $\begin{array}{l}\text { Crude or adjusted OR } \\
(95 \% \mathrm{Cl}), \mathrm{P} \text { for primary } \\
\text { comparison }\end{array}$ \\
\hline \multicolumn{12}{|c|}{ Urinary bacteria } \\
\hline 17 & 0 & 8833 & SA & MLR & Ec & $U$ & PDT & $\mathrm{Tr}$ & $\operatorname{Tr}$ & $0-6$ & $1.22(1.16$ to 1.28$) P<0.001$ \\
\hline \multirow[t]{2}{*}{19} & $\mathrm{CC}$ & 903 & SA & GP & Ec & $U$ & PDT & $\mathrm{Am}$ & Am & $0-12$ & 1.7 (1.24 to 2.32$)$ \\
\hline & & & & & Ec & $U$ & PDT & $\operatorname{Tr}$ & $\operatorname{Tr}$ & $0-12$ & 2.39 (1.62 to 3.53$)$ \\
\hline \multirow[t]{2}{*}{23} & $\mathrm{CC}$ & 3435 & SA & MLR & Ec & $U$ & PDT & AA & $\operatorname{Tr}$ & $0-6$ & $1.36(1.14$ to 1.60$)$ \\
\hline & & & & & Ec & $U$ & PDT & $\operatorname{Tr}$ & $\operatorname{Tr}$ & $0-6$ & 3.95 (3.04 to 5.12$)$ \\
\hline 24 & CC & 559 & SA & $\mathrm{OP}$ & $\mathrm{Ec}$ & $\mathrm{U}$ & PDT & ST, Q, P, AA & ST & $0-12$ & $4.1(2.20$ to 7.50$) \mathrm{P}=0.03$ \\
\hline \multirow[t]{2}{*}{18} & 0 & 618 & ASA & GP or POST & Ec & $U$ & PDT & AA & $\mathrm{Tr}, \mathrm{Am}$ & $0-12$ & $1.13(0.79$ to 1.63$)$ \\
\hline & & & & & Ec & $U$ & PDT & AA & $\mathrm{Tr}, \mathrm{Am}$ & $0-2$ & 1.93 (1.06 to 3.51) \\
\hline 25 & $\mathrm{CC}$ & 300 & SA & GP & Ec & $U$ & $M$ & O or Am & Q & $0-6$ & $0.26(0.09$ to 0.74$)$ \\
\hline 26 & OP & 35 & SC & GP & Ec & $U$ & PDT & $\mathrm{Su}$ & $\begin{array}{c}\text { Am, Str, Te, Ch, K, } \\
\text { Su, G, Tr, N }\end{array}$ & NR & $0.14(0.03$ to 0.56$) \mathrm{P}=0.9$ \\
\hline 27 & RCT & 131 & $\begin{array}{l}\text { SA women with } \\
\text { recurrent UTI }\end{array}$ & $\mathrm{OP}$ & Ec & $\mathrm{U}$ & PDT & $\mathrm{N}$ or $\mathrm{Cp}$ & $\mathrm{N}$ & $2-6 \mathrm{~W}$ & $0.67(0.30$ to 1.6$) \mathrm{P}=0.01$ \\
\hline \multicolumn{12}{|c|}{ Respiratory bacteria } \\
\hline 28 & $\mathrm{OP}$ & 119 & $\mathrm{SC}$ & GP & $\mathrm{H}$ & $\mathrm{T}$ & MIC & $\mathrm{Am}$ & $\mathrm{Am}$ & 2 & 1.9 (1.3 to 2.7$)$ p 0.001 \\
\hline 29 & CC & 145 & SA & GP & $\mathrm{Sp}$ & $T$ & PDT & $\mathrm{Ma}$ & $\mathrm{Ma}$ & $0-6 W$ & $2.11(1.05$ to 4.26$)$ \\
\hline 30 & $\mathrm{CC}$ & 412 & SA & GP & $\mathrm{Hi}$ & S & PDT & $A A$ & $\mathrm{Am}$ & $0-3$ & 2.1 (1.2 to 36.0) P<0.002 \\
\hline 31 & 0 & 263 & SC & GP & Spy & $T$ & PDT & $\mathrm{Ma}$ & $\mathrm{Ma}$ & $0-3$ & $4.19(1.23$ to 14.26$)$ \\
\hline 32 & $\mathrm{RCT}$ & 795 & SC & OP & $\mathrm{Sp}$ & NP & PDT & Sh Am or StAm & P, Am, Tr-Su & $0-2$ & 1.5 (1.2 to 2.8$) \mathrm{P}=0.001$ \\
\hline \multirow[t]{2}{*}{33} & 0 & 737 & SC & OP & Sp & NP & $E$ & $\mathrm{Cp}$ & $\begin{array}{l}\text { P, Ce, E, Tr, Su, } \\
\text { To, Cf, Cef, Te }\end{array}$ & $0-4$ & 2.3 (1.04 to 5.1) P<0.05 \\
\hline & & & & & $\mathrm{Sp}$ & $U$ & PDT & Not $\mathrm{Ma}$ & $\mathrm{Ma}$ & $0-6 W$ & 1.27 (0.64 to 2.54$)$ \\
\hline \multirow[t]{5}{*}{34} & CC & 134 & $\mathrm{SC}$ and $\mathrm{ASC}$ & PED & $\mathrm{Sp}$ & NP,OC,AN & $E$ & $\mathrm{~B}$ & $P$ & $0-1$ & - \\
\hline & & & & & $\mathrm{Sp}$ & NP,OR,AN & & Not B & $P$ & $0-1$ & 6.0 (0.06 to 516.4$)$ \\
\hline & & & & & $\mathrm{Sp}$ & NP,OR,AN & & B & $P$ & $0-6$ & $1.0(0.003$ to 255.6$)$ \\
\hline & & & & & $\mathrm{Sp}$ & NP,OR,AN & & Not B & $P$ & $0-6$ & 13.7 (0.6 to 311.48) \\
\hline & & & & & $\mathrm{Sp}$ & NP,OR,AN & & B + Oth & $\mathrm{P}$ & $0-6$ & $0.02(0.0007$ to 1.08$)$ \\
\hline \multirow[t]{2}{*}{35} & RCT & 224 & ASA & $\mathrm{U}$ & $\mathrm{Sp}$ & TON & GAP & $\mathrm{Az}$ & $\mathrm{Ma}$ & $8 \mathrm{D}$ & 1.86 (0.9 to 3.75) P<0.05 \\
\hline & & & & & $\mathrm{Sp}$ & TON & GAP & $\mathrm{Cl}$ & $\mathrm{Ma}$ & $8 \mathrm{D}$ & 2.47 (1.2 to 5.07$)$ \\
\hline 36 & CC & 448 & $\begin{array}{l}\text { Cwith suspected } \\
\text { otitis media }\end{array}$ & DCC & $\mathrm{Pn}$ & NP & PDT & $\mathrm{B}, \mathrm{Co}$, or $\mathrm{E}$ & $\mathrm{P}$ & $0-12$ & 8.8 (2.69 to 28.8$) \mathrm{P}<0.001$ \\
\hline \multirow[t]{7}{*}{37} & CC & 100 & A with COPD & $\mathrm{OP}$ & $\mathrm{Hi}$ & $\mathrm{S}$ & PDT & $P$ & B & $0-24$ & $2.15(0.94$ to 4.89$)$ \\
\hline & & & & & $\mathrm{Hi}$ & $\mathrm{S}$ & PDT & $\mathrm{Cp}$ & B & $0-24$ & 4.04 (1.22 to 13.4$)$ \\
\hline & & & & & $\mathrm{Hi}$ & $\mathrm{S}$ & PDT & Te & B & $0-24$ & 2.45 (1.09 to 5.49$)$ \\
\hline & & & & & $\mathrm{Hi}$ & $\mathrm{S}$ & PDT & $\mathrm{Ma}$ & B & $0-24$ & $4.04(1.22$ to 13.4$)$ \\
\hline & & & & & $\mathrm{Hi}$ & $\mathrm{S}$ & PDT & Co & B & $0-24$ & $1.94(0.82$ to 4.6$)$ \\
\hline & & & & & $\mathrm{Hi}$ & $\mathrm{S}$ & PDT & Q & B & $0-24$ & $2.13(0.5$ to 9.07$)$ \\
\hline & & & & & $\mathrm{Hi}$ & $\mathrm{S}$ & PDT & Oth & B & $0-24$ & $0.69(0.29$ to 1.61$)$ \\
\hline \multicolumn{12}{|l|}{ MRSA } \\
\hline \multirow[t]{3}{*}{38} & 0 & 167 & $\begin{array}{l}\text { A with skin } \\
\text { infection }\end{array}$ & GP & $\mathrm{Sa}$ & SK & PDT & AA & Me & $0-1$ & 2.7 (0.8 to 15.0) $P<0.1$ \\
\hline & & & & & $\mathrm{Sa}$ & SK & PDT & & $\mathrm{Me}$ & $0-6$ & 3.1 (1.1 to 8.6) P<0.01 \\
\hline & & & & & Sa & SK & PDT & & $\mathrm{Me}$ & $0-12$ & 1.5 (0.6 to 4.0) $P<0.4$ \\
\hline 39 & 0 & 206 & $\begin{array}{l}\text { A with skin } \\
\text { infection }\end{array}$ & MTC & Sa & SK & PDT & AA & $\mathrm{Me}$ & $0-12$ & $0.147(0.05$ to 0.4$) \mathrm{P}=0.123$ \\
\hline 40 & $\mathrm{CC}$ & 131 & $\begin{array}{l}\text { C with MRSA } \\
\text { positive } \mathrm{N} \\
\text { samples }\end{array}$ & PED & $\mathrm{Sa}$ & $\mathrm{N}$ & PDT & AA & $\mathrm{Me}$ & $0-12$ & $\begin{array}{c}16.13(6.38 \text { to } 40.76) \\
P<0.001\end{array}$ \\
\hline 41 & 0 & 840 & $\begin{array}{l}\text { C with Sa skin } \\
\text { infection }\end{array}$ & PED & $\mathrm{Sa}$ & SK & PDT & AA & $\mathrm{Me}$ & $0-3$ & 0.98 (0.67 to 1.42$)$ \\
\hline 42 & $\mathrm{RCT}$ & 1009 & $\begin{array}{l}\text { C with acute } \\
\text { otitis media }\end{array}$ & PED & GN & ST & PDT & Cf or $A m$ or $A z$ & CEFT, Cp, Am & 3-5D & $P<0.01 \dagger$ \\
\hline 43 & RCT & 121 & $\begin{array}{l}\text { C with early } \\
\text { trachoma }\end{array}$ & PED & $\mathrm{Ct}$ & OC & $E$ & $\mathrm{Az}$ & $\mathrm{Az}$ & $2 W$ & $\mathrm{P}=0.1 \dagger$ \\
\hline
\end{tabular}

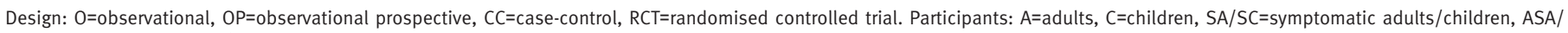

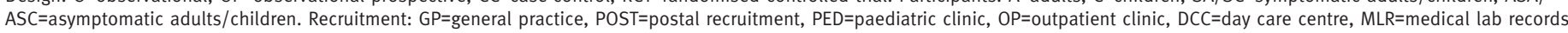
(routine laboratory samples linked to regional prescribing database), $\mathrm{MTC}=$ military training centre, $\mathrm{U}=$ university. $\mathrm{Bacteria}$ : $\mathrm{Ct}=C h l a m y d i a$ trachomatis, $\mathrm{Ec}=E \mathrm{C}$ coli, $\mathrm{GN}=$ gram negative,

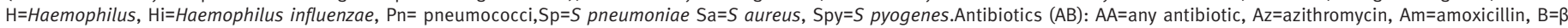
lactam, $\mathrm{Ce}=$ ceftriaxone, $\mathrm{Cf}=$ cefprozil, $\mathrm{Cef}=$ cefaclorR, $\mathrm{Cp}=$ cephalexin, $\mathrm{Cl}=$ clarithromycin, $\mathrm{Co}=\mathrm{co}$-trimoxazole, $\mathrm{E}=$ erythromycin, $\mathrm{G}=\mathrm{gentamicin}, \mathrm{K}=\mathrm{kenamycin}, \mathrm{Ma}=\mathrm{macrolide}, \mathrm{Me}=\mathrm{meticillin}$,

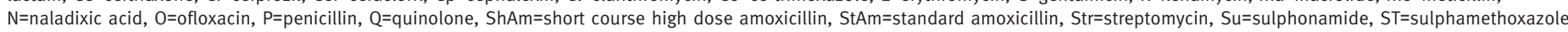

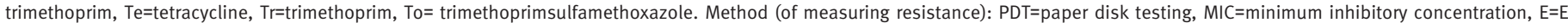

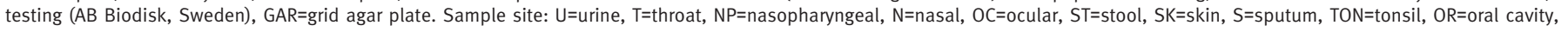
$\mathrm{AN}=$ anterior nares.

*Either exact time at which individuals took antibiotics, or time period during which antibiotic prescribing was recorded, before measurement of resistance.

tInsufficient data to calculate $\mathrm{OR}$ and/or $95 \% \mathrm{Cl}$ and/or $\mathrm{P}$ value. 
periods the odds of resistance were greater in patients exposed to these antibiotics than in those who were unexposed and that the strongest association was at 0-1 months, with reduced association at subsequent time points, and a small but important residual association within 12 months. In participants who were unexposed to antibiotics, the pooled odds of resistance varied little between time periods (pooled odds of resistance among unexposed participants was 0.44 at 0-1 month, fig 2). The $\beta$ coefficient for each month increase in the exposure period was $-0.33(95 \% \mathrm{CI}$ -0.49 to $-0.17, \mathrm{P}<0.001)$ from the meta-regression showing a clear time trend. There was no evidence of within group heterogeneity in the $0-1$ and $0-3$ month periods, but some evidence of heterogeneity in the

\begin{tabular}{|c|c|c|}
\hline $\begin{array}{l}\text { Time period, } \\
\text { study }\end{array}$ & $\begin{array}{l}\text { Antibiotic } \\
\text { exposure }\end{array}$ & \\
\hline \multicolumn{3}{|l|}{ 0-1 month } \\
\hline Donnan ${ }^{17}$ & Trimethoprim & \\
\hline Hillier ${ }^{19}$ & Trimethoprim & \\
\hline Hillier ${ }^{19}$ & Amoxicillin & \\
\hline
\end{tabular}

Pooled odds ratio

Test for heterogeneity: $\mathrm{I}^{2}=0.0 \%, \mathrm{P}=0.576$

$\begin{array}{lll}\text { 0-3 months } & & \\ \text { Donnan }^{17} & \text { Trimethoprim } & \text { NR } \\ \text { Hillier }^{19} & \text { Trimethoprim } & 39 \\ \text { Hillier }^{19} & \text { Amoxicillin } & 39 \\ \text { Hay }^{18} & \text { Any antibiotic } & 20\end{array}$

Pooled odds ratio

Test for heterogeneity: $I^{2}=0.0 \%, P=0.796$

\section{0-6 months \\ Steinke ${ }^{23}$ Any antibiotic* \\ Donnan ${ }^{17}$ Trimethoprim \\ Steinke ${ }^{23}$ Trimethoprim \\ Hillier ${ }^{19} \quad$ Amoxicillin \\ Donnan $^{17}$ Any antibiotic* \\ Hillier $^{19}$ Trimethoprim \\ Metlay $^{24} \quad$ ST}

Pooled odds ratio

Test for heterogeneity: $I^{2}=89.2 \%, P=0.000$

\section{0-12 months}

Donnan ${ }^{17}$ Trimethoprim

Donnan $^{17}$ Any antibiotic*

Hillier ${ }^{19} \quad$ Amoxicillin

Hay $^{18} \quad$ Any antibiotic*

Hillier $^{19} \quad$ Trimethoprim

Pooled odds ratio

Test for heterogeneity: $\left.\right|^{2}=71.9 \%, P=0.007$

0.1

\section{Antibiotic use} associated with susceptibility

* Any antibiotic other than trimethoprim. ST=sulfamethoxazole-trimethoprim. NR=not reported

Fig 2 | Forest plot showing individual study and pooled ORs (log scale) for resistance in urinary tract bacteria ( $E$ coli) and antibiotic exposure. Studies grouped according to time period during which exposure was measured and ordered within each time period by increasing standard error
0-6 month and 0-12 month periods. For studies in which adjusted $O R$ s were presented we did a meta-analysis of these results, although we only had sufficient data to do this for the studies examining resistance in urinary tract bacteria at the $0-3$ month period. The resulting pooled OR did not differ markedly from the unadjusted or crude OR used in the meta-regression at the same time point (pooled adjusted OR 2.17, 95\% CI 1.49 to 3.22 ), compared with 2.48 (2.06 to 2.98 )

\section{Resistance in respiratory bacteria}

Nine studies examined resistance in respiratory tract bacteria. ${ }^{28-3537}$ Since the Malhotra-Kumar ${ }^{35}$ and Chung studies ${ }^{28}$ were prospective and measured resistance at specific time points, their data are presented separately from the remaining retrospective studies measuring antibiotic exposure during periods of time. The Sportel study $^{37}$ measured resistance over a $0-24$ month period in a group of patients with chronic obstructive pulmonary disease (in which the lower respiratory tract becomes colonised with different bacteria from those usually resident in the upper respiratory tract ${ }^{44}$ ) so it was not included in the meta-analysis. The remaining seven studies were meta-analysed according to time periods. ${ }^{29-3436}$ Figure 3 shows that although there was some evidence of an association between antibiotics and resistance between 0 and 1 month (with an OR of 2.1,95\% CI 1.0 to 4.2), 0 and 2 months (pooled OR 2.4, 95\% CI 1.4 to 3.9), and 0 and 12 months (pooled OR $2.4,95 \%$ CI 1.3 to 4.5 ), intervening periods showed less evidence of such associations, and no association between resistance and time with a $\beta$ coefficient of $-0.01(95 \% \mathrm{CI}-0.26$ to $0.24, \mathrm{P}=0.91)$. We found little within group heterogeneity with the most heterogeneity present in the $0-12$ month period with an $\mathrm{I}^{2}$ value of $57.3 \%(\mathrm{P}=0.04)$. Among participants who were unexposed to antibiotics the pooled odds of resistance varied across time periods (fig 3) from 0.08 in the 0-2 month period to 0.51 during the $0-3$ month period. Some studies did not report raw data and for these studies the odds of resistance in the control group could not be calculated.

The Chung study ${ }^{28}$ used minimum inhibitory concentrations of ampicillin as a measure of antibiotic resistance and also presence of the integrative and conjunctive element ICEHin 1056 that encodes $\beta$-lactamase and circulates among nasopharyngeal Haemophilus species. Prescribing amoxicillin to a child in general practice more than tripled the mean inhibitory concentration for ampicillin $(9.2 \mu \mathrm{g} / \mathrm{ml}$ compared with $2.7 \mu \mathrm{g} / \mathrm{ml}, \mathrm{P}=0.005)$ and doubled the risk of isolation of Haemophilus isolates possessing homologues of ICEHin 1056 (67\%, 42 of 63, compared with $36 \%, 14$ of 39 in patients who were not exposed to antibiotic) with a relative risk of 1.9 (95\% CI 1.2 to 2.9$)$ at two weeks post-exposure and 1.0 (0.5 to 1.7$)$ at 12 weeks post-exposure. ${ }^{28}$

The Malhotra-Kumar study ${ }^{35}$ was the only randomised controlled trial to examine resistance (associated with azithromycin or clarithromycin) at specific time points. Figure 4 and the meta-analysis of the pooled 
Table 2 | Study quality (by reference number)

\begin{tabular}{|c|c|c|c|c|c|c|c|c|}
\hline Study & $\begin{array}{l}\text { Data on antibiotic } \\
\text { exposure complete } \\
\text { and accurate? }\end{array}$ & $\begin{array}{c}\text { Resistance } \\
\text { well defined? }\end{array}$ & $\begin{array}{l}\text { Resistance } \\
\text { threshold } \\
\text { described? }\end{array}$ & $\begin{array}{l}\text { Unbiased } \\
\text { control } \\
\text { selection? }\end{array}$ & $\begin{array}{c}\text { Resistance status } \\
\text { known before } \\
\text { exposure? }\end{array}$ & $\begin{array}{l}\text { Adjustments } \\
\text { for } \\
\text { confounders? }\end{array}$ & $\begin{array}{l}\text { Adjusted OR } \\
(95 \% \mathrm{CI})\end{array}$ & $P$ \\
\hline 17 & Y & Y & $\mathrm{N}$ & $Y$ & Unknown & Y & $1.22(1.16$ to 1.28$))$ & $<0.001$ \\
\hline 19 & $\mathrm{Y}$ & Y & $\mathrm{Y}$ & Y & Unknown & $\mathrm{Y}$ & Not reported & - \\
\hline 23 & $\mathrm{Y}$ & Y & $\mathrm{N}$ & Y & Unknown & Y & $\begin{array}{l}4.35(3.03 \text { to } 5.73) \\
1.32(1.10 \text { to } 1.60)\end{array}$ & - \\
\hline 24 & $\mathrm{Y}$ & $Y$ & Y & $Y$ & Unknown & $\mathrm{Y}$ & $4.1(2.2$ to 7.5,$)$ & 0.03 \\
\hline \multirow[t]{2}{*}{18} & $\mathrm{Y}$ & Y & Y & $\mathrm{Y}$ & Unknown & $\mathrm{Y}$ & $1.12(0.77$ to 1.65$)$ & - \\
\hline & Y & Y & & Y & Unknown & Y & 1.95 (1.08 to 3.49$)$ & - \\
\hline 25 & $\mathrm{~N}$ & $\mathrm{Y}$ & $\mathrm{Y}$ & NA & Unknown & Y & $\begin{array}{l}\text { Ciprofloxacin } 20.6 \text { (2.4 to } 179.2), \\
\text { ofloxacin } 7.6 \text { (2.9 to } 19.5)\end{array}$ & $0.006,0.0001$ \\
\hline 26 & $\mathrm{~N}$ & Y & $\mathrm{Y}$ & NA & Unknown & Unknown & Not reported & - \\
\hline 27 & $\mathrm{Y}$ & $\mathrm{Y}$ & $\mathrm{Y}$ & NA & $\mathrm{Y}$ & Unknown & Not reported & - \\
\hline 28 & $\mathrm{Y}$ & $\mathrm{Y}$ & $\mathrm{Y}$ & $\mathrm{Y}$ & $\mathrm{Y}$ & $\mathrm{Y}$ & Not reported & - \\
\hline 29 & $\mathrm{~N}$ & Y & Y & Y & Unknown & $\mathrm{Y}$ & $1.0003(1.0001$ to 1.0004$)$ & $<0.0001$ \\
\hline 30 & Y & Y & Y & $\mathrm{Y}$ & Unknown & $\mathrm{Y}$ & 3.4 (1.3 to 9.2$)$ & $<0.01$ \\
\hline 31 & Y & Y & Y & $\mathrm{Y}$ & Unknown & Y & $2.16(0.55$ to 8.45$)$ & 0.26 \\
\hline 32 & $\mathrm{Y}$ & Y & Y & Y & Unknown & $\mathrm{Y}$ & Not reported & - \\
\hline 33 & $\mathrm{Y}$ & Y & Y & Y & Unknown & Y & 2.7 (1.1 to 6.6$)$ & $<0.001$ \\
\hline 34 & Y & Y & $\mathrm{Y}$ & Y & Unknown & Unknown & Not reported & - \\
\hline 35 & Y & Y & Y & Y & Y & Y & Not reported & - \\
\hline 36 & $\mathrm{Y}$ & Y & Y & Y & Unknown & Y & Not reported & - \\
\hline 37 & Y & Y & Y & Y & Unknown & $\mathrm{Y}$ & 1.15 (1.04 to 1.28$)$ & $<0.01$ \\
\hline 38 & Y & Y & Y & Y & Unknown & Y & Not reported & - \\
\hline 39 & Y & Y & Y & Y & Unknown & $\mathrm{Y}$ & Not reported & - \\
\hline 40 & Y & Y & $\mathrm{Y}$ & Y & Unknown & $\mathrm{Y}$ & $29.37(10.72$ to 80.50$)$ & $<0.001$ \\
\hline 41 & $\mathrm{~N}$ & Y & Y & Y & Unknown & Y & Not reported & - \\
\hline 42 & $\mathrm{~N}$ & $\mathrm{Y}$ & $\mathrm{Y}$ & No controls & Unknown & No & Not reported & - \\
\hline 43 & Y & Y & Not reported & Y & Unknown & Y & Not reported & - \\
\hline
\end{tabular}

OR showed a decaying association with resistance to macrolides at all time points up to 6 months with strong evidence of a time trend ( $\beta$ coefficient -0.25 (95\% CI -0.39 to $-0.11, \mathrm{p}=0.004) .^{35}$

\section{Resistance over time in MRSA studies}

We found few studies investigating effects on MRSA; three studies in skin samples ${ }^{383941}$ and one study in nasal samples. ${ }^{40}$ Paganini et $\mathrm{al}^{41}$ examined community acquired MRSA in children. These isolates were obtained from skin and soft tissue infections, and some invasive infection sites. The study found that $10 \%$ (26 of 273) of isolates were resistant to clindamycin as well as meticillin and 1\% (two of 272) were resistant to trimethoprim-sulfamethoxazole. Raw data obtained from the authors allowed the calculation of an OR for resistance of 0.98 (95\% CI 0.67 to 1.42$)$ suggesting that previous antibiotic use is not an important risk factor for community acquired MRSA isolated from children's skin infections. However, exposure data for this study relied on parental reports only.

Campbell et $\mathrm{al}^{39}$ examined community acquired MRSA in skin infections in healthy military trainees. Previous antibiotic use was not associated with MRSA infection (OR 0.7 (95\% CI 0.2 to 1.9 ).

Baggett et $\mathrm{al}^{38}$ investigated a large outbreak of community acquired MRSA in a rural community and found a strong association (OR 3.1, 95\% CI 1.1 to 8.6) between this infection and the prescription of any antibiotic in the previous $0-6$ months. This association disappeared $(1.5,0.6$ to 4.0$)$ when the time period was broadened to include any antibiotic prescription in the preceding 12 months.

Lo et $\mathrm{al}^{40}$ examined resistance associated with the use of any antibiotic in the 12 months preceding resistance testing. This study reported a strong association of OR 16.1 (95\% CI 6.4 to 40.8 ) between previous antibiotic use and nasal colonisation of Panton-Valentine leukocidin positive MRSA in healthy children.

We did a meta-analysis of the three studies investigating MRSA and resistance in bacteria sampled from skin abrasions ${ }^{383941}$ in which individuals had been exposed to antibiotics in the previous 12 months; the pooled OR for these studies was 1.04 , with the confidence interval crossing the null (95\% CI 0.47 to 2.29$)$.

\section{Comparisons between antibiotics}

Many of the studies included in the review looked at head to head comparisons between antibiotics, although their statistical power was often limited. For example, the Ghaffar study ${ }^{34}$ examined resistance to penicillin in Streptococcus pneumoniae following use of $\beta$ lactam drugs or $\beta$ lactam in combination with another antibiotic class but the $95 \%$ confidence intervals around the estimated OR varied from 0.1 to 516 . 


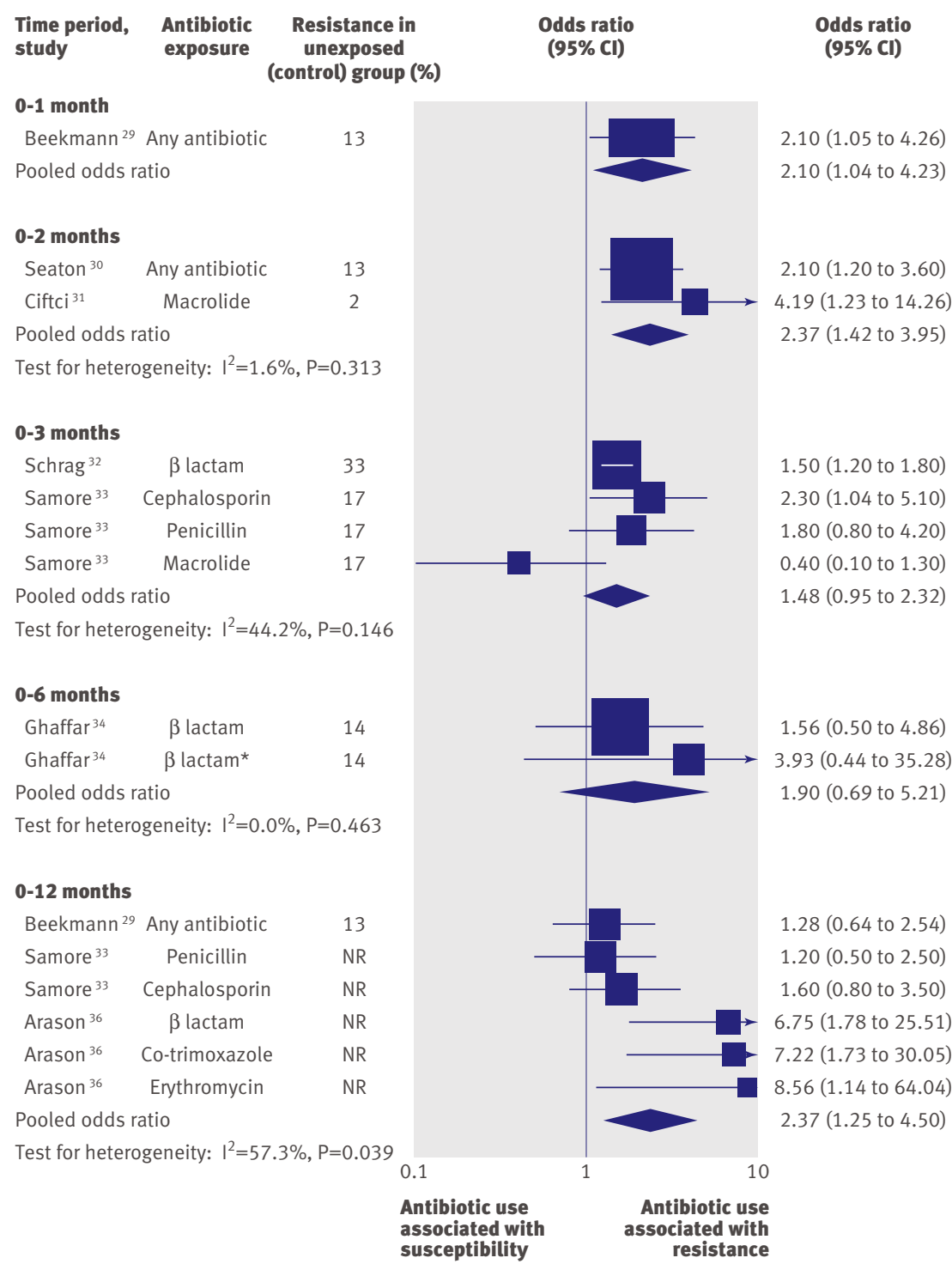

* $\beta$ lactam plus another antibiotic. NR=not reported

Fig 3 | Forest plot showing individual study and pooled ORs (log scale) for resistance in respiratory tract bacteria and previous antibiotic prescribing. Studies grouped according to time period during which exposure was measured and ordered within each time period by increasing standard error
Effects of antibiotic dose, duration, and number of courses on resistance

Several studies assessed the relation between resistance and increasing courses of or doses of antibiotic (table 3). Schrag et $\mathrm{al}^{32}$ compared the effect of standard dose and duration of amoxicillin with that of high dose and short duration amoxicillin on resistance at 5,10 , and 28 days. They reported some evidence of reduced resistance at 28 days associated with this treatment (OR 0.77, 95\% CI 0.06 to 0.97 ), possibly attributable to better compliance. Hillier et $\mathrm{al}^{19}$ found greater rates of resistance associated with higher doses of amoxicillin (OR 2.3, 95\% CI 1.1 to 4.6 ) and longer courses of trimethoprim $(2.9,1.4$ to 5.8$)$, but no differences associated with different course durations for amoxicillin $(1.5,0.7$ to 2.9$)$.

Hillier also found associations between number of courses of amoxicillin (three or more $v$ one; OR 3.9, 95\% CI 1.0 to 14.7 ) and trimethoprim (three or more $v$ one; $3.6,1.2$ to 10.5 ) and resistance. ${ }^{19}$ The Hay study ${ }^{18}$ showed no differences in resistance rates with differing numbers of antibiotic courses, but did find an increase of $1 \%$ in the odds of resistance for each $200 \mathrm{mg}$ trimethoprim tablet prescribed (OR 1.01, 95\% CI 1.01 to 1.02$)$. The same type of association was not found for increasing numbers of $500 \mathrm{mg}$ amoxicillin tablets prescribed.

\section{Publication bias}

We were able to assess publication bias in the urinary bacteria studies investigating resistance in $E$ coli and antibiotic exposure in the previous six months. The Funnel plot in fig 5 shows some evidence of positive publication bias. There were too few studies to assess publication bias for respiratory flora.

\section{DISCUSSION}

\section{Principal findings}

Our review identified a number of studies that together provide strong evidence of an association at the individual patient level between the prescribing of antibiotics in primary care and antimicrobial resistance in bacteria at different sites, including the urinary and respiratory tracts and the skin. Effects were strongest in the month directly after prescription but were detectable for up to 12 months. This residual effect is likely to be an important driver for the high endemic levels of antibiotic resistance in the community. ${ }^{28}$ Moreover, we found evidence of a dose-response relation for two commonly prescribed first line antibiotics in primary care, amoxicillin and trimethoprim.

\section{Prescribing time periods}

Most studies that reported resistance in urinary and respiratory bacteria reported the association between resistance and antibiotics prescribed within overlapping time periods. This means that associations with longer time periods could reflect long or short term relations. However, the prospective studies did not suffer from this methodological weakness and did suggest persistence of resistance over a number of months. ${ }^{2835}$
To summarise, in comparisons of different antibiotics in the same antibiotic classes for effects on resistance, we found no evidence that one class led to reduced resistance compared with another, although we were unable to adequately address the issue owing to the limited number of studies available. 


\section{Time period}

At 1 week post-antibiotic

Azithromycin

Clarithromycin

Pooled odds ratio

At $\mathbf{2}$ weeks post-antibiotic Azithromycin

Clarithromycin

Pooled odds ratio

At 1 month post-antibiotic Azithromycin

Pooled odds ratio

At 2 months post-antibiotic Azithromycin

Clarithromycin

Pooled odds ratio

At 6 months post-antibiotic Azithromycin

Clarithromycin

Pooled odds ratio
Clarithromycin

Odds ratio $(95 \% \mathrm{Cl})$

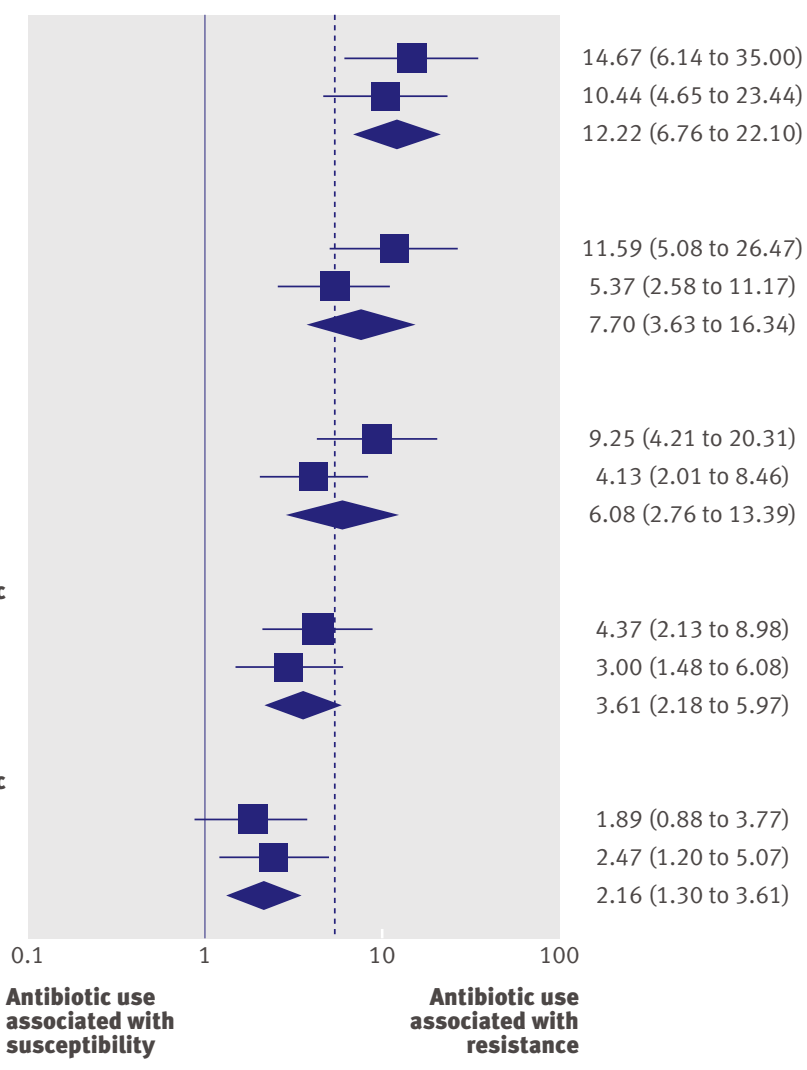

Fig 4 | Forest plot showing individual analytic and pooled ORs (log scale) for resistance in respiratory tract streptococci of healthy volunteers from the Malhotra-Kumar study ${ }^{35}$ and previous antibiotic prescribing

\section{Reverse causality and confounding}

If bacterial samples are taken only if the illness does not respond to first line antibiotics (as is standard practice in many parts of the UK) then retrospective case-control analyses will show a spuriously strong association with previous antibiotic prescribing. This bias is avoided if only incident cases are included. For most of the studies reviewed it was not possible to ascertain whether non-incident cases had been excluded. This bias is less likely, although not impossible, in

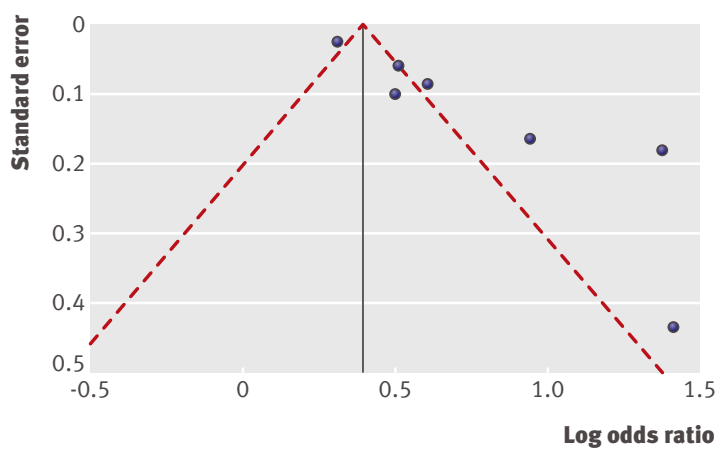

Fig 5 | Funnel plot with pseudo $95 \%$ confidence limits for studies investigating the relation between resistance in urinary bacteria and antibiotic use in the previous six months prospective studies than in retrospective ones. However, both of the prospective studies eliminated reverse causality as a possible explanation by collecting baseline resistance data; they showed substantial increases in resistance within days of prescribing and subsequent decay in effects over three months in the Chung study (28) and six months in the Malhotra-Kumar study. ${ }^{35}$ Other confounding associations, such as the relation between community prescribing and recent hospital admission, could also have introduced bias. However, the studies that attempted to adjust for potential confounders such as age, sex, comorbidities, catheter use, and smoking status seldom demonstrated substantial difference between crude and adjusted estimates of association.

\section{Heterogeneity between studies}

The observed differences between studies may well reflect the difficulties of overlapping time periods and confounding, but could also reflect the differences in populations studied (which must have varied in baseline prevalence of antibiotic resistance and transmission potential), the definition of resistance applied, and the different antibiotic-organism relationships studied. Residual heterogeneity was a particular problem in the pooled analyses of urinary bacteria in the 0-6 month and 0-12 month periods and in the analyses of respiratory bacteria in the $0-12$ period. As previously noted, this heterogeneity existed despite some evidence of publication bias.

\section{MRSA studies}

Hospital MRSA strains are becoming feral, persisting in the community, and non-hospital epidemic strains are being acquired in the community. ${ }^{45}$ Although two of the studies suggest that the selective pressure produced by antibiotic prescribing in the community may contribute to this problem, the other two showed no effect. The mechanism of MRSA transmission is clearly complex and to explore this issue further, repeated screening of large numbers of individuals (mostly non-carriers) would be necessary over a long period. In the meantime, minimisation of unnecessary community prescribing for skin infections seems a reasonable precautionary principle.

\section{Clinical and research implications}

This review provides the evidence needed by clinicians responsible for the prescription of antibiotics in primary care to quantify the link between individual prescribing decisions and the problem of antibiotic resistance. Although the clinical impact of isolating antibiotic resistant bacteria warrants further research in its own right, resistance is not simply a characteristic of the infecting organism. It is also related to the individual's bacterial gene pool, since resistance carried on plasmids and integrons can be transferred between commensal organisms and potential pathogens. And because both transmission of commensal organisms between individuals and antibiotic prescribing in the 
Table $3 \mid$ Relations between antibiotic dose and resistance (by reference number)

\begin{tabular}{|c|c|c|c|c|c|}
\hline Study & $\begin{array}{l}\text { High dose/ } \\
\text { concentration }\end{array}$ & $\begin{array}{l}\text { Standard dose } \\
\text { and duration }\end{array}$ & $\begin{array}{l}\text { Antibiotic to which } \\
\text { resistance was measured }\end{array}$ & Time* & OR $(95 \% \mathrm{Cl})$ \\
\hline \multirow[t]{3}{*}{ Schrag $2001^{32}$} & $\begin{array}{l}\text { High dose amoxicillin } \\
90 \mathrm{mg} / \mathrm{kg} \text { for } 5 \text { days }\end{array}$ & $\begin{array}{l}\text { Normal dose amoxicillin } \\
40 \mathrm{mg} / \mathrm{kg} \text { per day for } 10 \text { days }\end{array}$ & Penicillin & 5 days & 0.9 (0.6 to 1.2$)$ \\
\hline & & & & 10 days & $1.16(0.88$ to 1.53$)$ \\
\hline & & & & 28 days & 0.77 (0.06 to 0.97$)$ \\
\hline \multirow[t]{3}{*}{ Hillier $2007^{19}$} & High dose amoxicillin 500 mg & Normal dose amoxicillin $250 \mathrm{mg}$ & Ampicillin & $0-12$ months & $2.26(1.13$ to 4.55$)$ \\
\hline & Amoxicillin $>7$ days & Amoxicillin $<7$ days & Ampicillin & $0-12$ months & 1.50 (0.76 to 2.92$)$ \\
\hline & Trimethoprim $>7$ days & Trimethoprim $<7$ days & Ampicillin & $0-12$ months & 2.89 (1.44 to 5.78$)$ \\
\hline \multirow[t]{4}{*}{ Hillier $2007^{19}$} & 2 courses amoxicillin & 1 course amoxicillin & Ampicillin & $0-12$ months & 1.58 (0.77 to 3.27$)$ \\
\hline & 3 courses amoxicillin & 1 course amoxicillin & Ampicillin & $0-12$ months & 3.95 (1.06 to 14.72$)$ \\
\hline & 2 courses trimethoprim & 1 course trimethoprim & Trimethoprim & $0-12$ months & 0.98 (0.39 to 2.49$)$ \\
\hline & 3 courses trimethoprim & 1 course trimethoprim & Trimethoprim & $0-12$ months & $3.62(1.25$ to 10.48$)$ \\
\hline \multirow[t]{5}{*}{ Hay $2005^{18}$} & 2 courses any antibiotic & 1 course any antibiotic & Trimethoprim & $0-12$ months & 1.18 (0.53 to 2.37$)$ \\
\hline & 3 courses any antibiotic & 1 course any antibiotic & Trimethoprim & $0-12$ months & $0.4(0.12$ to 1.31$)$ \\
\hline & 4 courses any antibiotic & 1 course any antibiotic & Trimethoprim & $0-12$ months & 2.77 (0.94 to 8.15$)$ \\
\hline & $\begin{array}{l}\text { Increasing dose of trimethoprim by } \\
200 \mathrm{mg}\end{array}$ & Normal dose of trimethoprim & Trimethoprim & $0-12$ months & 1.01 (1.01 to 1.02$)$ \\
\hline & Increasing dose of $\beta$ lactam by $500 \mathrm{mg}$ & Normal dose of $\beta$ lactam & Amoxicillin & $0-12$ months & $1.00(0.99$ to 1.01$)$ \\
\hline
\end{tabular}

*Either exact time at which individuals took antibiotics, or time period during which antibiotic prescribing was recorded, before measurement of resistance.

community remain frequent events, even a transient effect of antibiotic use on the carriage of resistant organisms by an individual could have a major impact on the endemic level of resistance in the population. ${ }^{28}$

Our findings also provide evidence to support the Standing Medical Advisory Committee report recommendations that the fewest number of antibiotic courses should be prescribed for the shortest period possible. ${ }^{3}$ And they draw attention to the increased risk of resistance to commonly used first line antibiotics: if a patient has received one or more courses of such antibiotics in the previous 12 months and further antibiotic treatment is necessary, for a subsequent respiratory or urinary infection, consideration

\section{WHAT IS ALREADY KNOWN ON THIS TOPIC}

Worldwide, primary care is responsible for the majority of antibiotic use by human beings

Although many countries have reduced prescribing rates, substantial variations remain between countries

Many clinicians and patients do not see antibiotic resistance as a reason to refrain from antibiotic use

\section{WHAT THIS STUDY ADDS}

Antibiotics prescribed to an individual in primary care were consistently found to be associated with resistance of urinary and respiratory bacteria to those antibiotics in that individual

Antibiotics prescribed in primary care may impact on bacterial resistance in a patient for up to 12 months

The greater the number or duration of antibiotic courses prescribed in the previous 12 months, the greater the likelihood that resistant bacteria would be isolated from that patient should be given to choosing a different antibiotic. This final implication serves to highlight that the only way to avoid the vicious cycle of resistance leading to the ever greater use of more powerful broad spectrum antibiotics is to avoid their initial use whenever possible.

The main research implication is the need to strengthen the current evidence base, which is heavily reliant on observational studies, with more clinical trials. We believe that the opportunity to assess the effects of antibiotics on antimicrobial resistance should be considered whenever a placebo or "no treatment" controlled trial is being designed. Further research is also needed to assess relations between antibiotics prescribed in primary care and more serious infections that require secondary care treatment, as well as to further clarify the effects of interactions between antibiotic dose, duration, and adherence on resistance.

In conclusion, we have summarised and synthesised evidence from around the world that primary care antibiotics make an important contribution to the problem of antimicrobial resistance. Primary care clinicians and patients may wish to consider this evidence when discussing the benefits and risks of prescribing and consuming antibiotics.

Contributors: CC performed the searches. CC and ADH identified eligible studies. All authors appraised study quality and extracted data. CC and $\mathrm{CM}$ transformed data and performed the meta-analyses. CC and ADH drafted first sections of the text. All authors contributed to the final draft. $\mathrm{ADH}$ and $\mathrm{CC}$ are the guarantors. All authors had full access to all of the data (including statistical reports and tables) in the study and can take responsibility for the integrity of the data and the accuracy of the data analysis.

Funding: This work was undertaken by the University of Bristol in collaboration with the University of Oxford which both received a proportion of their funding from the Department of Health's NIHR School for Primary Care Research. The views expressed in this publication are those of the authors and not necessarily those of the Department of Health. The funder had no role in the study design; data collection, data analysis, and interpretation of data; in the writing of the report; or in the 
decision to submit the article for publication. The researchers were independent of the funder.

Competing interests: All authors have completed the Unified Competing Interest form at www.icmje.org/coi_disclosure.pdf (available on request from the corresponding author) and declare that (1) CC, ADH, DM, AL, and CM have support from the Universities of Bristol and Oxford for the submitted work; (2) None of the authors has relationships with any companies that might have an interest in the submitted work in the previous 3 years; (3) None of the authors' spouses, partners, or children have any financial relationships that may be relevant to the submitted work; and (4) None of the authors has any non-financial interests that may be relevant to the submitted work

Ethical approval: Not required.

Data sharing: No additional data available.

1 Department of Health. UK antimicrobial resistance strategy and action plan. 2000.www.dh.gov.uk/prod_consum_dh/groups/ dh_digitalassets/@dh/@en/documents/digitalasset/ dh 4078448.pdf.

2 Butler CC, Hillier S, Roberts Z, Dunstan F, Howard A, Palmer S. Antibiotic-resistant infections in primary care are symptomatic for longer and increase workload: outcomes for patients with E coli UTIs. Br J Gen Pract 2006;56:686-92.

3 Department of Health. The path of least resistance. 1998. www.dh. gov.uk/prod_consum_dh/groups/dh_digitalassets/@dh/@en/ documents/digitalasset/dh_4120729.pdf.

4 Prescription Pricing Authority. Trends in antibiotic prescribing in England. 2006. www.ppa.org.uk/news/pact-102004.htm.

5 Ashworth M, Charlton J, Ballard K, Latinovic R, Gulliford M. Variations in antibiotic prescribing and consultation rates for acute respiratory infection in UK practices 1995-2000. Br J Gen Pract 2005;55:603-8.

6 Ferech M, Coenen S, Malhotra-Kumar S, Dvorakova K, Hendrickx E, Suetens $C$, et al. European surveillance of antimicrobial consumption (ESAC): outpatient antibiotic use in Europe. J Antimicrob Chemother 2006;58:401-7.

7 Macfarlane J, Holmes W, Macfarlane R, Britten N. Influence of patients' expectations on antibiotic management of acute lower respiratory tract illness in general practice: questionnaire study. $B M$ J 1997;315:1211-4.

8 Brooks L, Shaw A, Sharp D, Hay AD. Towards a better understanding of patients' perspectives of antibiotic resistance and MRSA: a qualitative study. Fam Pract 2008;25:341-8.

9 Butler CC, Rollnick S, Pill R, Maggs-Rapport F, Stott N. Understanding the culture of prescribing: qualitative study of general practitioners' and patients' perceptions of antibiotics for sore throats. BMJ 1998;317:637-42.

10 Kumar S, Little P, Britten N. Why do general practitioners prescribe antibiotics for sore throat? Grounded theory interview study. BMJ 2003;326:138.

11 Seppala H, Klaukka T, Vuopio-Varkila J, Muotiala A, Helenius H, Lager $\mathrm{K}$, et al. The effect of changes in the consumption of macrolide antibiotics on erythromycin resistance in group A streptococci in Finland. N Engl J Med 1997;337:441-6.

12 Priest P, Yudkin P, McNulty C, Mant D, Wise R. Antibacterial prescribing and antibacterial resistance in English general practice: cross sectional study. Commentary: antibiotic resistance is a dynamic process. BMJ 2001;323:1037-41.

13 Lipsitch M, Samore MH. Antimicrobial use and antimicrobial resistance: a population perspective. Emerg Infect Dis 2002;8:347-54.

14 Simpson SA, Wood F, Butler CC. General practitioners' perceptions of antimicrobial resistance: a qualitative study. J Antimicrob Chemother 2007;59:292-6.

15 NICE. Respiratory tract infections: prescribing of antibiotics for selflimiting respiratory tract infections in adults and children in primary care. 2008. www.nice.org.uk/CG69.

16 Hillier SL, Magee JT, Howard AJ, Palmer SR. How strong is the evidence that antibiotic use is a risk factor for antibiotic-resistant, community-acquired urinary tract infection? J Antimicrob Chemother 2002;50:241-7.

17 Donnan PT, Wei L, Steinke DT, Phillips G, Clarke R, Noone A, et al. Presence of bacteriuria caused by trimethoprim resistant bacteria in patients prescribed antibiotics: multilevel model with practice and individual patient data. BM/ 2004:328:1297-300.

18 Hay AD, Thomas M, Montgomery A, Wetherell M, Lovering A, McNulty C, et al. The relationship between primary care antibiotic prescribing and bacterial resistance in adults in the community: controlled observational study using individual patient data. $/$ Antimicrob Chemother 2005;56:146-53.

19 Hillier S, Roberts Z, Dunstan F, Butler C, Howard A, Palmer S. Prior antibiotics and risk of antibiotic-resistant community-acquired urinary tract infection: a case-control study. J Antimicrob Chemother 2007;60:92-9.
20 Stroup DF, Berlin JA, Morton SC, Olkin I, Williamson GD, Rennie D, et al. Meta-analysis of observational studies in epidemiology: a proposal for reporting. JAMA 2000;283:2008-12.

21 Moher D, Cook DJ, Eastwood S, Olkin I, Rennie D, Stroup DF. Improving the quality of reports of meta-analyses of randomised controlled trials: the QUOROM statement. Onkologie 2000;23:597-602

22 Moher D, Liberati A, Tetzlaff J, Altman DG. Preferred reporting items for systematic reviews and meta-analyses: the PRISMA statement. Clin Epidemiol 2009;62:1006-12.

23 Steinke DT, Seaton RA, Phillips G, MacDonald TM, Davey PG. Prior trimethoprim use and trimethoprim-resistant urinary tract infection: nested case-control study with multivariate analysis for other risk factors. J Antimicrob Chemother 2001;47:781-7.

24 Metlay JP, Strom BL, Asch DA. Prior antimicrobial drug exposure: a risk factor for trimethoprim-sulfamethoxazole-resistant urinary trac infections. J Antimicrob Chemother 2003;51:963.

25 Colodner R, Kometiani I, Chazan B, Raz R. Risk factors for communityacquired urinary tract infection due to quinolone-resistant $\mathrm{E}$ coli. Infection 2008;36:41-5.

26 Grunberg RN, Shaw EJ. The influence of antibiotic treatment on resistance patterns of coliform bacilli in childhood urinary-tract infection. I Med Microbiol 1976;9:233-7.

27 Preiksaitis JK, Thompson L, Harding GKM, Marie TJ, Hoban S, Ronald AR. A comparison of the efficacy of nalidixic acid and cephalexin in bacteriuric women and their effect on fecal and periurethral carriage of enterobacteriaceae. J Infect Dis 1981;143:603-8.

28 Chung A, Perera R, Brueggemann AB, Elamin AE, Harnden A, Mayon-White $R$, et al. Effect of antibiotic prescribing on antibiotic resistance in individual children in primary care: prospective cohort study. BMJ 2007;335:429-34.

29 Beekmann SE, Diekema DJ, Heilmann KP, Richter SS, Doern GV. Macrolide use identified as risk factor for macrolide-resistant Streptococcus pneumoniae in a 17-center case-control study. Eur J Clin Microbiol Infect Dis 2006;25:335-9.

30 Seaton RA, Steinke DT, Phillips G, MacDonald T, Davey PG Community antibiotic therapy, hospitalization and subsequent respiratory tract isolation of Haemophilus influenzae resistant to amoxycillin: a nested case-control study. J Antimicrob Chemother 2000;46:307-9.

31 Ciftci E, Dogru U, Guriz H, Aysev D, Ince E. Investigation of risk factors for tonsillopharyngitis with macrolide resistant Streptococcus pyogenes in Turkish children. Pediatr Int 2002;44:647-51.

32 Schrag SJ, Pena C, Fernandez J, Sanchez J, Gomez V, Perez E, et al. Effect of short-course, high-dose amoxicillin therapy on resistant pneumococcal carriage: a randomized trial. JAMA 2001;286:49-56.

33 Samore MH, Magill MK, Alder SC, Severina E, Morrison-De Boer L, Lyon JL, et al. High rates of multiple antibiotic resistance in Streptococcus pneumoniae from healthy children living in isolated rural communities: association with cephalosporin use and intrafamilial transmission. Pediatrics 2001;108:856-65.

34 Ghaffar F, Muniz LS, Katz K, Smith JL, Shouse T, Davis P, et al. Effects of large dosages of amoxicillin/clavulanate or azithromycin on nasopharyngeal carriage of Streptococcus pneumoniae, Haemophilus influenzae, nonpneumococcal alpha-hemolytic streptococci, and Staphylococcus aureus in children with acute otitis media. Clin Infect Dis 2002;34:1301-9.

35 Malhotra-Kumar S, Lammens C, Coenen S, Van Herck K, Goossens H. Effect of azithromycin and clarithromycin therapy on pharyngeal carriage of macrolide-resistant streptococci in healthy volunteers: a randomised, double-blind, placebo-controlled study. Lancet 2007;369:482-90.

36 Arason VA, Kristinsson KG, Sigurdsson JA, Stefansdottir G, Molstad S, Gudmundsson S. Do antimicrobials increase the carriage rate of penicillin resistant pneumococci in children? Cross sectional prevalence study. BMJ 1996;313:387-91.

37 Sportel JH, Koeter GH, van Altena R, Lowenberg A, Boersma WG. Relation between beta-lactamase producing bacteria and patient characteristics in chronic obstructive pulmonary disease (COPD). Thorax 1995;50:249-53.

38 Baggett HC, Hennessy TW, Rudolph K, Bruden D, Reasonover A, Parkinson A, et al. Community-onset methicillin-resistan Staphylococcus aureus associated with antibiotic use and the cytotoxin Panton-Valentine leukocidin during a furunculosis outbreak in rural Alaska. J Infect Dis 2004;189:1565-73.

39 Campbell KM, Vaughn AF, Russell KL, Smith B, Jimenez DL, Barrozo CP, et al. Risk factors for community-associated methicillin resistant Staphylococcus aureus infections in an outbreak of disease mong military trainees in San Diego, California, in 2002. I Clin Microbiol 2004;42:4050-3.

40 Lo WT, Lin WJ, Tseng MH, Lu J), Lee SY, Chu ML, et al. Nasal carriage of a single clone of community-acquired methicillin-resistant Staphylococcus aureus among kindergarten attendees in northern Taiwan. BMC Infect Dis 2007;7:51. 
41 Paganini H, la Latta MP, Muller OB, Ezcurra G, Uranga M, Aguirre C, et al. [Community-acquired methicillin-resistant Staphylococcus aureus infections in children: multicenter trial]. Arch Argent Pediatr 2008;106:397-403.

42 Toltzis P, Dul M, O’Riordan MA, Toltzis H, Blumer JL. Comparative effects of single-dose ceftriaxone versus three oral antibiotic regimens on stool colonization by resistant bacilli in children. Pediat Infect Dis / 2007;26:25-30.

43 Chern KC, Shrestha SK, Cevallos V, Dhami HL, Tiwari P, Chern L, et al. Alterations in the conjunctival bacterial flora following a single dose of azithromycin in a trachoma endemic area. Br J Ophthalmol 1999;83:1332-5.

44 Sethi S. Bacteria in exacerbations of chronic obstructive pulmonary disease: phenomenon or epiphenomenon? Proc Am Thorac Soc 2004;1:109-14.

45 Miller R, Walker AS, Knox K, Wyllie D, Paul J, Haworth E, et al. "Feral" and "wild"-type methicillin-resistant Staphylococcus aureus in the United Kingdom. Epidemiol Infect 2009;1-11.

Accepted: 19 March 2010 